\title{
Reliability and Validity of Household Disaster Preparedness Index (HDPI)
}

\author{
Mehdi Najafi ${ }^{1,2,},{ }^{*}$ Hamidreza Khankeh ${ }^{3}$, Ahmad Soltani $^{4,5}$ and Golrokh Atighechian ${ }^{6}$ \\ 1 Postdoctoral Researcher, Health in Emergency and Disaster Research Center, University of Social Welfare and Rehabilitation Sciences, Tehran, Iran \\ ${ }^{2}$ Assistant Professor, Research Center for Emergency and Disaster Resilience, Red Crescent Society of the Islamic Republic of Iran, Tehran, Iran \\ 3 Professor, Health in Emergency and Disaster Research Center, University of Social Welfare and Rehabilitation Sciences, Tehran, Iran \\ ${ }^{4}$ Research Center for Emergency and Disaster Resilience, Red Crescent Society of the Islamic Republic of Iran, Tehran, Iran \\ ${ }^{5}$ Iran-Helal Institute of Applied-Science and Technology, Red Crescent Society of the Islamic Republic of Iran, Tehran, Iran \\ ${ }^{6}$ Assistant Professor, Health Management and Economics Research Center, Isfahan University of Medical Sciences, Isfahan, Iran
}

* Corresponding author: Mehdi Najafi, Health in Emergency and Disaster Research Center, University of Social Welfare and Rehabilitation Sciences, Tehran, Iran. Tel: +982188974897; Email: najafirc@gmail.com

Received 2020 0ctober 15; Revised 2020 0ctober 27; Accepted 2020 November 05.

\begin{abstract}
Background: The preparedness of families for disasters can set auspicious grounds for the preparedness of the whole society. In the health system of Iran, the Household Disaster Preparedness Index (HDPI) composed of 15 items is applied for the assessment of household preparedness in disasters.

Objectives: The current study was carried out in order to investigate the reliability and validity of the HDPI.

Methods: Two methods, namely internal consistency and stability determination, were utilized for the investigation of HDPI reliability. Face validity, content validity, and construct validity were examined for the assessment of HDPI validity. Accordingly, in addition to interviewing with experts and family heads, 200 families were selected from a study population, including the families in all the counties of Isfahan province, Iran, based on multistage cluster sampling. Both qualitative and quantitative methods were used for the investigation of content validity. Furthermore, exploratory factor analysis was the method of choice for the examination of construct validity.

Results: The rate of HDPI internal consistency was calculated at 0.786 which was within an acceptable range. Moreover, HDPI stability was computed at 0.98 using the test-retest method which was also within an optimal level. Therefore, it can be stated that the HDPI enjoys the required reliability. The investigation of HDPI face validity indicated that the families have problems in perceiving some of the items of this index. The experts put forward suggestions for the improvement of HDPI content validity following the qualitative investigation of content validity. In the examination of content validity ratio, all the items except those numbered 1,3 , and 4 were within an acceptable range; however, the investigation of the content validity index demonstrated that only the validity of the items numbered 12 and 13 was acceptable regarding all the three scales of relevancy, clarity, and simplicity. For the determination of construct validity, exploratory factor analysis was applied to extract five factors (i.e., subscales), namely the reduction of vulnerability, planning for disasters, family empowerment, procurement of resources for disasters, and specialized programs. The investigation of the internal consistency of the aforementioned subscales indicated that only the internal consistency of the first and second factors was within an acceptable range.

Conclusion: The results of the present study revealed that although the HDPI is a reliable measure, it does not enjoy the required validity for the assessment of household preparedness for disasters.
\end{abstract}

Keywords: Disaster, Household, Index, Preparedness

\section{Background}

During recent years, the term preparedness has gained a special prevalence in the studies conducted on the reduction of disaster risk. However, this common term is not often clearly and similarly discerned and various individuals have their own special perception of this term, which is usually general and ambiguous. Such ambiguity has caused it to be practically difficult to measure the extent of preparedness at various levels. In addition, extravagant budgets are occasionally spent on interventions that are termed preparatory intervenetions; however, it is not clear as to how much these interventions cause preparedness augmentation.

Among all the communities that form the society, the family is of special importance. In fact, as the smallest social unit, the family plays a substantial role in the emergence of society and its economic, social, and cultural performance. The families' preparedness in disasters can set auspicious grounds for the whole society's preparedness. In various studies, certain indices have been used for the measurement of family or household preparedness. In some of the aforementioned studies, the reliability and validity of the used instrument have been pointed out. For example, Ardalan et al. have introduced a tool for the assessment of preparedness for earthquakes which is comprised of six categories and 18 items. They have stated that the content validity index (CVI) of the items of this instrument is within the range of 0.8-1 and all its items are valid enough. Moreover, they have also demonstrated the good reliability of the aforementioned instrument based on Cronbach's alpha calculated at 0.7 and results obtained from testretest ( 1 ).

However, in many of the studies, nothing has been mentioned about the reliability and validity of the 


\begin{tabular}{|c|c|c|c|}
\hline \multirow{2}{*}{$\begin{array}{ll}\text { No. } \\
1\end{array}$} & \multirow{2}{*}{$\begin{array}{l}\text { Question } \\
\text { Have any sessions been held in your family during the last year in order to plan for confrontation with } \\
\text { disasters? }\end{array}$} & \multicolumn{2}{|c|}{ Answer } \\
\hline & & Yes $\square$ & No \\
\hline 2 & Has your family drawn a risk map for important disasters? & Yes $\square$ & No $\square$ \\
\hline 3 & Has the strength of your house been evaluated against earthquakes during the last year by a specialist? & Yes $\square$ & No $\square$ \\
\hline 4 & $\begin{array}{l}\text { Have you taken any measures during the last year for the reinforcement of your house building against } \\
\text { earthquakes? }\end{array}$ & Yes $\square$ & No $\square$ \\
\hline 5 & $\begin{array}{l}\text { Have you evaluated the vulnerability of the nonstructural components of your house to earthquakes during } \\
\text { the last year? }\end{array}$ & Yes $\square$ & No $\square$ \\
\hline 6 & $\begin{array}{l}\text { Have you taken any measures during the last year for the reduction of the vulnerability of your house's } \\
\text { nonstructural components? }\end{array}$ & Yes $\square$ & No $\square$ \\
\hline 7 & Are there any emergency and disaster kits in your house? & Yes $\square$ & No $\square$ \\
\hline 8 & Does your family have a communication plan for emergency and disaster conditions? & Yes $\square$ & No $\square$ \\
\hline 9 & Does your family have an evacuation plan for emergency and disaster conditions? & Yes $\square$ & No \\
\hline 10 & $\begin{array}{l}\text { Are there any special plans in your family for helping vulnerable groups under emergency and disaster } \\
\text { conditions? }\end{array}$ & Yes $\square$ & No $\square$ \\
\hline 11 & $\begin{array}{l}\text { Are your family members familiar with early warnings against the region's important hazards, such as floods } \\
\text { and storms? }\end{array}$ & Yes $\square$ & No $\square$ \\
\hline 12 & Are there any fire extinction tools in your house? & Yes $\square$ & No $\square$ \\
\hline 13 & Has at least one of your family members been instructed during the last year for medical first aid? & Yes $\square$ & No \\
\hline 14 & Does your family take part in disaster management programs in the neighborhood? & Yes $\square$ & No $\square$ \\
\hline 15 & Has your family performed emergency and disaster exercises during the last year? & Yes $\square$ & No $\square$ \\
\hline
\end{tabular}

instrument even with the use of an instrument for the assessment of disaster preparedness. For instance, Helene Joffe et al. have utilized an instrument with 9 items for the evaluation of preparedness for earthquakes and fires; nevertheless, no reference has been made to reliability and validity $(r)$. In addition, another study carried out by Chaney et al. has used an instrument with uncertain reliability and validity for the assessment of families' preparedness for tornados $\left({ }^{\top}\right)$.

Der-Martirosian et al. utilized an instrument with unclear reliability and validity for the comparison of veterans' families with others $\left({ }^{*}\right)$. Furthermore, in order to investigate the relationship between residence type and family's preparedness for disasters, Murti et al. used an instrument without mentioning anything about its reliability and validity (d). Furthermore, some studies have made general references to the reliability and validity of the instruments used in their studies.

For instance, another study conducted by Chan et al. utilized an instrument for the evaluation of preparedness; nonetheless, it has only been stated that its validity was tested in a local population $\left({ }^{4}\right)$. Uscher-Pines et al. in determining the extent of preparedness and resilience reported that they have used an instrument enjoying the required reliability and validity $(\vee)$. One of the indices defined by Iran Ministry of Health and Medical Education and used for the assessment of families' preparedness for disasters is the Household Disaster Preparedness Index (HDPI) which consists of 15 items as presented in Table $1(\wedge)$.

\section{Objectives}

There has been no study carried out on the assessment of the reliability and validity of the HDPI. Therefore, the present study was carried out to assess the reliability and validity of the HDPI.

\section{Methods}

\subsection{Reliability}

In order to investigate the reliability of the HDPI, two methods were employed, namely internal consistency (correlation) and stability determination. Cronbach's alpha (or coefficient alpha) was calculated for a 200-individual sample size composed of the family heads in all the counties in Isfahan province, Iran. The calculation of the item-to-scale coefficient is the method of determining if the answers to each of the given items match with the pattern of answers related to other items or not and it is actually the correlation coefficient of the respondents' scores in that item with their scores in the rest of the scale. As this coefficient becomes bigger, the item belongs more to the scale. Based on an empirical maxim, if this coefficient is calculated at below 0.3 for an item, it should be omitted from the scale ( $\left.{ }^{9}\right)$. The -retest method was used in order to evaluate HDPI stability. The questionnaire was administered to a group of 30 family heads in one of the counties in Isfahan province in two stages within a 2-week interval. Then, the scores acquired in these two stages were compared using an intraclass correlation coefficient. Indices higher than 0.8 were considered indicative of optimal stability $(1 \cdot)$.

\subsection{Validity}

Face validity, content validity, and construct validity tests were performed in order to investigate HDPI validity. Two methods, namely qualitative and quantitative, were utilized for the assessment of face validity. In the qualitative investigation of face validity, face-to-face interviews were carried out with 10 family heads in Isfahan province about the cases of difficulty (i.e., difficulty in the perception of the 
expressions and words) and ambiguity (i.e., the likelihood of the mistaken perceptions of the expressions and/or existence of insufficiency in the words' meanings). The extent of relevancy (i.e., the appropriate relevance and relatedness of the expressions to the questionnaire's aspects) could not be assessed since the dimensions of the questionnaire were not specified.

Two qualitative and quantitative methods were applied in order to perform the content validity test. In the qualitative content validity test, 11 experts with the knowledge and experience of the disaster risk management domains were asked to provide the required feedbacks following the investigation of HDPI items based on scales, such as the observance of correct grammar, use of appropriate wording, and necessity and importance of the items, their placement in their right positions (i.e., item allocation), and proper scoring (i.e., scaling). In the quantitative content validity examination, content validity ratio (CVR) was utilized in order to ensure that the most important and correct content (i.e., most necessary items) has been selected. In addition, in order to make sure that the items of the instrument have been designed in the best way for the measurement of the content, the CVI was utilized.

Firstly, for the determination of CVR, 20 experts (different from the experts in the previous stage) were asked to investigate every item based on a three-part spectrum (i.e., It is necessary, It is useful but not necessary, and It is not necessary). Based on the Lawshe table, the items with acceptable CVR values (CVR of $\geq 0.42$ for 20 experts) were determined. Then, the CVI was investigated based on Waltz and Bausell's CVI ( 1 ). Accordingly, the HDPI was presented to the specialists for the determination of the extent of relevancy, simplicity, and clarity of all the expressions therein. Through this method, these three scales, namely simplicity, relevancy, and clarity, were separately investigated based on a 4-point Likert scale for each of the items by 20 experts (different from the specialists in the previous stages). As an instance, the choices were applied for relevancy as 1=irrelevant, 2=relatively relevant, $3=$ relevant, and $4=$ completely relevant.

The score of the content validity of each expression was calculated by dividing the number of the experts confirming the expression with ranks 3 and 4 by the total number of all the experts ( $I$ ). The scores equal to 0.79 and higher were set as the criterion for the acceptance of the items according to the CVI level ( 1 r). In the next stage and based on the mean CVI score of all the HDPI items, the mean scale level of content validity index (S-CVI/Ave) was calculated. Scores equal to 0.90 and higher were considered acceptable for S-CVI/Ave ( 1 r).

In order to investigate construct validity and since there was no presupposition of the dimensions constituting the HDPI, exploratory factor analysis was utilized for identifying the classes of items with the highest interrelatedness ( $\left.{ }^{\leftarrow}\right)$. To use this method, firstly, the internal consistency of HDPI items were examined. Then, Kaiser-Meyer-Olkin (KMO) test was performed for the investigation of sampling adequacy, and Bartlett's test of sphericity (BTS) was carried out in order to demonstrate the satisfactory suitability of the data for factor analysis. After clarifying that factor analysis is a proper method for the current data, Cattell's scree test was applied to determine the number of extractable factors; then, varimax rotation was utilized to perform exploratory factor analysis on 15 items of the HDPI using principal component analysis.

\subsection{Sample size and sampling method}

The number of subjects required for performing factor analysis, parallel to the determination of construct validity, is different from the perspective of various researchers. The number of recommended participants for performing factor analysis was within the range of 5-10 subjects per every item of the instrument $\left(1^{\leftarrow}\right)$. In the present study, although a sample of families comprised of 10 times higher than the number of the items (i.e. 150 families regarded as sufficient), 50 extra subjects were also allowed to enter the study to acquire better results in factor analysis and 200 families were eventually chosen for factor analysis (this same sample size was also used for the investigation of HDPI internal consistency). Multistage cluster sampling was utilized in order to select this 200-individual sample size from the families in all the counties of Isfahan province.

Firstly, the counties were classified into eight sets based on socioeconomic conditions. Then, one city was selected from each class in a simple randomized manner. Subsequently, a district was chosen from the urban regions also in a simple randomized manner. Afterward, one neighborhood was selected from every chosen district again in a simple randomized manner. One building block was selected in the chosen neighborhood based on the aforementioned simple randomized method. Finally, several houses were randomly chosen from the houses in the chosen block in proportion to the study sample size.

\section{Results}

Reliability is a necessary condition for validity ( $(\downarrow)$. Therefore, firstly the reliability and secondly validity of the HDPI were investigated in the present study.

\subsection{Investigating the reliability of $H D P I$}

\subsubsection{Investigating the internal consistency of HDPI}

The internal consistency of the HDPI was calculated at 0.786 . Considering the fact that the level of internal consistency within the range of 0.7-0.9 is often appropriate ( 17 ), the internal consistency of the 


\begin{tabular}{lcccc}
\hline \multicolumn{4}{l}{ Table 2. Internal consistency of the Household Disaster Preparedness Index } \\
\hline Item & $\begin{array}{c}\text { Scale mean if item } \\
\text { removed }\end{array}$ & $\begin{array}{c}\text { Scale variance if item } \\
\text { removed }\end{array}$ & $\begin{array}{c}\text { Corrected item-total } \\
\text { correlation }\end{array}$ & $\begin{array}{c}\text { Cronbach's alpha if } \\
\text { item removed }\end{array}$ \\
\hline $\mathbf{1}$ & 3.650 & 8.751 & 0.318 & 0.779 \\
$\mathbf{2}$ & 3.635 & 8.293 & 0.532 & 0.764 \\
$\mathbf{3}$ & 3.500 & 8.080 & 0.475 & 0.766 \\
$\mathbf{4}$ & 3.410 & 8.022 & 0.453 & 0.768 \\
$\mathbf{5}$ & 3.260 & 8.892 & 0.428 & 0.765 \\
$\mathbf{6}$ & 3.370 & 8.244 & 0.357 & 0.778 \\
$\mathbf{7}$ & 3.640 & 8.925 & 0.218 & 0.786 \\
$\mathbf{8}$ & 3.670 & 8.916 & 0.259 & 0.783 \\
$\mathbf{9}$ & 3.575 & 8.386 & 0.405 & 0.773 \\
$\mathbf{1 0}$ & 3.615 & 8.409 & 0.441 & 0.770 \\
$\mathbf{1 1}$ & 3.220 & 8.012 & 0.440 & 0.770 \\
$\mathbf{1 2}$ & 3.670 & 8.147 & 0.134 & 0.790 \\
$\mathbf{1 3}$ & 3.520 & 8.969 & 0.538 & 0.761 \\
$\mathbf{1 4}$ & 3.625 & 8.628 & 0.347 & 0.777 \\
$\mathbf{1 5}$ & 3.560 & 8.348 & 0.408 & 0.772 \\
\hline
\end{tabular}

HDPI was reported as appropriate. The findings of the present study indicated that item 7 (with a correlation coefficient equal to 0.218 ) and item 12 (with a correlation coefficient equal to 0.134 ) did not conform to the intended scale; therefore, the two aforementioned items should be removed from the HDPI (Table 2).

\subsection{Investigating the stability of HDPI}

The stability of the HDPI was calculated at 0.98 using the test-retest method and reported at an optimum level (Table 3).

Considering the appropriate internal consistency and optimal stability of the HDPI, it can be stated that this index features the required stability.

\subsection{Investigating the validity of HDPI}

\subsubsection{Face validity}

Since the dimensions of the HDPI questionnaire have not been separately identified, it was not possible to examine the relevance of the items to the aspects; however, the findings obtained from the investigation of the difficulty and ambiguity levels of the questionnaire indicated that the family heads had difficulty in understanding some of the expressions (Table 4).

Table 3. Correlation between the scores obtained from the two tests for the investigation of the stability of the Household Disaster Preparedness Index

\begin{tabular}{llcc}
\hline & & ScoreT1 & ScoreT2 \\
\hline \multirow{4}{*}{ ScoreT1 } & Pearson correlation & 1 & $0.981^{* *}$ \\
& Sig. (2-tailed) & & 0.000 \\
& $\mathrm{n}$ & 30 & 30 \\
\multirow{5}{*}{ ScoreT2 } & Pearson correlation & $0.981^{* *}$ & 1 \\
& Sig. (2-tailed) & 0.000 & \\
& $\mathrm{n}$ & 30 & 30 \\
\hline$* *$ Correlation & significant at the & 30 .
\end{tabular}

** Correlation significant at the level of 0.01 (2-tailed)

\begin{tabular}{|c|c|c|c|}
\hline No. & Item & Difficulty level & Ambiguity \\
\hline 1 & $\begin{array}{l}\text { Have any sessions been held in your family during the last year for making plans to confront } \\
\text { the disasters? }\end{array}$ & $\begin{array}{c}\text { Nearly } \\
\text { understandable }\end{array}$ & $\begin{array}{l}\text { Somewhat } \\
\text { ambiguous }\end{array}$ \\
\hline 2 & Has your family drawn a risk map for important disasters? & Difficult & Ambiguous \\
\hline 3 & $\begin{array}{l}\text { Has the strength of your house been evaluated against earthquakes during the last year by a } \\
\text { specialist? }\end{array}$ & $\begin{array}{l}\text { Nearly } \\
\text { understandable }\end{array}$ & $\begin{array}{l}\text { Somewhat } \\
\text { ambiguous }\end{array}$ \\
\hline 4 & $\begin{array}{l}\text { Have you taken any measures during the last year for the reinforcement of your house } \\
\text { building against earthquakes? }\end{array}$ & $\begin{array}{l}\text { Nearly } \\
\text { understandable }\end{array}$ & $\begin{array}{l}\text { Somewhat } \\
\text { ambiguous }\end{array}$ \\
\hline 5 & $\begin{array}{l}\text { Have you evaluated the vulnerability of the nonstructural components of your house to } \\
\text { earthquakes during the last year? }\end{array}$ & Difficult & Ambiguous \\
\hline 6 & $\begin{array}{l}\text { Have you taken any measures during the last year for the reduction of the vulnerability of } \\
\text { your house nonstructural components? }\end{array}$ & Difficult & Ambiguous \\
\hline 7 & Are there any emergency and disaster kits in your house? & Difficult & Ambiguous \\
\hline 8 & Does your family have a communication plan for emergency and disaster conditions? & Difficult & Ambiguous \\
\hline 9 & Does your family have an evacuation plan for emergency and disaster conditions? & Understandable & Clear \\
\hline 10 & $\begin{array}{l}\text { Are there any special plans in your family for helping vulnerable groups under emergency and } \\
\text { disaster conditions? }\end{array}$ & $\begin{array}{l}\text { Nearly } \\
\text { understandable }\end{array}$ & $\begin{array}{l}\text { Somewhat } \\
\text { ambiguous }\end{array}$ \\
\hline 11 & $\begin{array}{l}\text { Are your family members familiar with the preliminary warnings for the region's important } \\
\text { hazards, such as floods and storms? }\end{array}$ & $\begin{array}{c}\text { Nearly } \\
\text { understandable }\end{array}$ & Clear \\
\hline 12 & Are there any fire extinction tools in your house? & Understandable & Clear \\
\hline 13 & Has at least one of your family members been instructed during the last year for medical first aid? & Understandable & Clear \\
\hline 14 & Does your family take part in disaster management programs in the neighborhood? & $\begin{array}{c}\text { Nearly } \\
\text { understandable }\end{array}$ & $\begin{array}{l}\text { Somewhat } \\
\text { ambiguous }\end{array}$ \\
\hline 15 & Has your family performed emergency and disaster exercises during the last year? & $\begin{array}{c}\text { Nearly } \\
\text { understandable }\end{array}$ & Clear \\
\hline
\end{tabular}




\begin{tabular}{|c|c|c|}
\hline No. & Item & $\begin{array}{c}\text { The following words and } \\
\text { combinations should be replaced by } \\
\text { appropriate equivalents }\end{array}$ \\
\hline 1 & $\begin{array}{l}\text { Have any sessions been held in your family during the last year for making plans to } \\
\text { confront the disasters? }\end{array}$ & Making plans and disasters \\
\hline 2 & Has your family drawn a risk map for important disasters? & Drawn a risk map \\
\hline 3 & $\begin{array}{l}\text { Has the strength of your house been evaluated against earthquakes during the last } \\
\text { year by a specialist? }\end{array}$ & $\begin{array}{l}\text { Evaluation, strength of your house, and } \\
\text { specialist }\end{array}$ \\
\hline 4 & $\begin{array}{c}\text { Have you taken any measures during the last year for the reinforcement of your } \\
\text { house building against earthquakes? }\end{array}$ & Reinforcement of your house building \\
\hline 5 & $\begin{array}{l}\text { Have you evaluated the vulnerability of the nonstructural components of your house } \\
\text { to earthquakes during the last year? }\end{array}$ & $\begin{array}{l}\text { Vulnerability and nonstructural } \\
\text { components }\end{array}$ \\
\hline 6 & $\begin{array}{l}\text { Have you taken any measures during the last year for the reduction of the } \\
\text { vulnerability of your house nonstructural components? }\end{array}$ & $\begin{array}{l}\text { Vulnerability and nonstructural } \\
\text { components }\end{array}$ \\
\hline 7 & Are there any emergency and disaster kits in your family? & Emergency and disaster kits \\
\hline 8 & Does your family have a communication plan for emergency and disaster conditions? & Communication plan \\
\hline 9 & Does your family have an evacuation plan for emergency and disaster conditions? & Evacuation plan \\
\hline 10 & $\begin{array}{l}\text { Are there any special plans in your family for helping vulnerable groups under } \\
\text { emergency and disaster conditions? }\end{array}$ & Vulnerable groups \\
\hline 11 & $\begin{array}{l}\text { Are your family members familiar with the preliminary warnings for the region's } \\
\text { important hazards, such as floods and storms? }\end{array}$ & Preliminary warnings \\
\hline 12 & Are there any fire extinction tools in your house? & Fire extinction tools \\
\hline 13 & $\begin{array}{c}\text { Has at least one of your family members been instructed during the last year for } \\
\text { medical first aid? }\end{array}$ & 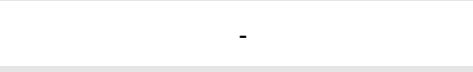 \\
\hline 14 & Does your family take part in disaster management programs in the neighborhood? & $\begin{array}{l}\text { Disaster management programs in the } \\
\text { neighborhood }\end{array}$ \\
\hline 15 & Has your family performed emergency and disaster exercises during the last year? & $\begin{array}{c}\text { Exercises for emergency and disaster } \\
\text { conditions }\end{array}$ \\
\hline
\end{tabular}

\subsection{Investigating the content validity of HDPI}

\subsubsection{Qualitative investigation of the content validity}

The qualitative investigation of the content validity of the HDPI was carried out by 10 experts based on scales, such as the observance of grammar, use of proper wording, and necessity and importance of the items, their placement in their right positions, and proper scoring. With regard to the use of proper wording, the experts put forward some suggestions (Table 5). As for the necessity and importance of the items and their placement in the right positions, the experts asserted that all the items were necessary and important and they were used in their right positions. Concerning the scoring of the items, the experts believed that the scoring should include a spectrum (for example within 0-10) in lieu of using two scores (i.e., 0 and 1 ) based on the number of measures taken by the families.

\subsubsection{Quantitative investigation of the content validity}

Regarding the CVR, the items numbered 1,3 , and 4 did not show the minimum acceptable coefficient of the CVR considering the fact that the acceptance score was 0.42 and higher. The CVR of the rest of the items was within an acceptable range. The results of the CVI analysis indicated that the validity rates of all the choices were acceptable in terms of relevancy; however, only the validity rates of the items numbered $3,4,12$, and 13 were confirmed with regard to clarity. Concerning simplicity, only the validity rates of the items numbered 9, 12, and 13 were affirmed. In other words, only the validity rates of the items numbered 12 and 13 were accepted in terms of all the three scales of relevancy, clarity, and simplicity (Table 6). The HDPI S-CVI/Ave was calculated at 0.72 which was not acceptable for this instrument due to the fact that the acceptance level has been set at 0.90 and higher.

\subsection{Investigating the construct validity of HDPI}

As observed in the section on reliability investigation, the correlation coefficient of each of the items of the HDPI was calculated with respect to the whole scale. It was clarified that items 7 (with a correlation coefficient equal to 0.218 ) and 12 (with a correlation coefficient equal to 0.134) did not correlate with the whole HDPI scale and should be actually removed (Table 2). However, the aforementioned items were not excluded from exploratory factor analysis performed below and the judgment about them has been left to the designers of the scale.

Table 6. Content validity index and content validity ratio of the Household Disaster Preparedness Index

\begin{tabular}{|c|c|c|c|c|c|c|c|c|c|c|c|c|c|c|c|c|}
\hline \multirow{2}{*}{\multicolumn{2}{|c|}{ CVI and CVR }} & \multicolumn{15}{|c|}{ Item } \\
\hline & & 1 & 2 & 3 & 4 & 5 & 6 & 7 & 8 & 9 & 10 & 11 & 12 & 13 & 14 & 15 \\
\hline \multirow{3}{*}{ CVI } & Relevancy & 1 & 0.95 & 0.9 & 0.8 & 1 & 1 & 1 & 1 & 1 & 0.9 & 0.9 & 1 & 1 & 0.9 & 1 \\
\hline & Clarity & 0.65 & 0.3 & 0.85 & 0.8 & 0.3 & 0.4 & 0.85 & 0.25 & 0.75 & 0.3 & 0.75 & 0.95 & 0.8 & 0.75 & 0.6 \\
\hline & Simplicity & 0.6 & 0.2 & 0.7 & 0.65 & 0.2 & 0.3 & 0.75 & 0.35 & 0.85 & 0.35 & 0.6 & 0.95 & 0.8 & 0.65 & 0.6 \\
\hline CVR & & 0 & 0.5 & -0.5 & -0.2 & 0.5 & 1 & 1 & 1 & 0.8 & 0.8 & 0.7 & 1 & 1 & 0.5 & 0.8 \\
\hline
\end{tabular}

CVI: Content validity index; CVR: Content validity ratio 


\begin{tabular}{|c|c|c|c|c|c|c|c|c|c|c|c|c|c|c|c|}
\hline Item & 1 & 2 & 3 & 4 & 5 & 6 & 7 & 8 & 9 & 10 & 11 & 12 & 13 & 14 & 15 \\
\hline 1 & 1 & 0.516 & 0.189 & 0.042 & 0.104 & 0.041 & 0.144 & 0.102 & 0.356 & 0.229 & 0.103 & 0.054 & 0.279 & 0.081 & 0.118 \\
\hline 2 & 0.516 & 1 & 0.218 & 0.126 & 0.168 & 0.119 & 0.161 & 0.218 & 0.530 & 0.429 & 0.279 & 0.173 & 0.436 & 0.216 & 0.227 \\
\hline 3 & 0.189 & 0.218 & 1 & 0.629 & 0.443 & 0.341 & 0.069 & 0.030 & 0.042 & 0.143 & 0.171 & 0.030 & 0.290 & 0.225 & 0.260 \\
\hline 4 & 0.042 & 0.126 & 0.629 & 1 & 0.508 & 0.393 & 0.019 & 0.095 & 0.021 & 0.162 & 0.262 & -0.005 & 0.183 & 0.215 & 0.243 \\
\hline 5 & 0.104 & 0.168 & 0.443 & 0.508 & 1 & 0.353 & -0.016 & 0.114 & 0.091 & 0.184 & 0.358 & -0.046 & 0.227 & 0.246 & 0.356 \\
\hline 6 & 0.041 & 0.119 & 0.341 & 0.393 & 0.353 & 1 & 0.015 & 0.097 & 0.055 & 0.150 & 0.145 & -0.001 & 0.294 & 0.177 & 0.171 \\
\hline 7 & 0.144 & 0.161 & 0.069 & 0.019 & -0.016 & 0.015 & 1 & 0.042 & 0.295 & 0.248 & 0.154 & 0.227 & 0.188 & 0.146 & -0.006 \\
\hline 8 & 0.102 & 0.218 & 0.030 & 0.095 & 0.114 & 0.097 & 0.042 & 1 & 0.257 & 0.317 & 0.215 & -0.021 & 0.156 & 0.203 & 0.045 \\
\hline 9 & 0.356 & 0.530 & 0.042 & 0.021 & 0.091 & 0.055 & 0.295 & 0.257 & 1 & 0.408 & 0.226 & 0.217 & 0.292 & 0.125 & 0.179 \\
\hline 10 & 0.229 & 0.429 & 0.143 & 0.162 & 0.184 & 0.150 & 0.248 & 0.317 & 0.408 & 1 & 0.258 & 0.188 & 0.228 & 0.107 & 0.154 \\
\hline 11 & 0.103 & 0.279 & 0.171 & 0.262 & 0.358 & 0.145 & 0.154 & 0.215 & 0.226 & 0.258 & 1 & 0.054 & 0.319 & 0.157 & 0.325 \\
\hline 12 & 0.054 & 0.173 & 0.030 & -0.005 & -0.046 & -0.001 & 0.227 & -0.021 & 0.217 & 0.188 & 0.054 & 1 & 0.156 & -0.062 & 0.083 \\
\hline 13 & 0.279 & 0.436 & 0.290 & 0.183 & 0.227 & 0.294 & 0.188 & 0.156 & 0.292 & 0.228 & 0.319 & 0.156 & 1 & 0.345 & 0.346 \\
\hline 14 & 0.081 & 0.216 & 0.225 & 0.215 & 0.246 & 0.177 & 0.146 & 0.203 & 0.125 & 0.107 & 0.157 & -0.067 & 0.345 & 1 & 0.206 \\
\hline 15 & 0.118 & 0.227 & 0.260 & 0.243 & 0.365 & 0.171 & -0.006 & 0.045 & 0.179 & 0.154 & 0.325 & 0.083 & 0.346 & 0.206 & 1 \\
\hline
\end{tabular}

\begin{tabular}{lcc}
\hline \multicolumn{2}{l}{ Table 8. Kaiser-Meyer-Olkin test and Bartlett's test of sphericity } \\
\hline \multicolumn{3}{l}{ Kaiser-Meyer-Olkin measure of sampling adequacy } \\
\hline \multirow{3}{*}{ Bartlett's test of sphericity } & Approx. Chi-square & 0.786 \\
& df & 703.708 \\
& Sig. & 105 \\
\end{tabular}

4.6. Data matrix determinant, KMO test, and Bartlett's test of sphericity for the investigation of the appropriateness of factor analysis

Data matrix determinant was calculated at 0.026 (Table 7). Since it is larger than 0.00001 , there is no multicollinearity between the items ( $\mathrm{V}$ ). In other words, there is no strong correlation between the items; as a result, they can be isolated from one another.

In order to investigate the sample size adequacy, a level equal to 0.8 and higher is considered appropriate $(1 \wedge)$. In the present study, the KMO level was computed at 0.786 which was indicative of the adequacy of the sample size for the factor classification and principal component analysis. Furthermore, BTS showed the difference between the items of the correlation matrix and identity matrix (with p-values of $<0.001$ and $\mathrm{X}^{2}{ }_{(105)}$ $=703.708$ ). The test significance was reflective of the idea that there is enough correlation in the matrix of the items for the subsequent performing of factor analysis (Table 8). In sum, data matrix determinant, KMO test, and BTS confirmed the initial proportion of the data for factor analysis.

\subsection{Findings obtained from Cattell's scree test}

The number of extractable factors is illustrated in a diagram as the output of Cattell's scree test (Diagram 1). As it is shown in Diagram 1, only four or five factors can be extracted and the slope of the curve becomes subsequently parallel to the x-axis. Of course, Cattell's scree is a visual test and only provides the researcher with a preliminary suggestion. Consequently, the theoretical issues should be taken into account for selecting the number of factors.

4.8. Structural (Factorial) credibility and internal reliability of the subscales of HDPI

Exploratory factor analysis was carried out on 15 items of the HDPI using principal component analysis. In this analysis, the varimax rotation method was used and initial eigenvalues larger than unity were the scale of choice. After analyzing the principal components for the identification of the factorial structure's pattern present in the items, five factors (i.e., subscales) were extracted (Table 9). These five factors, including vulnerability reduction, planning for disaster, family empowerment, preparation of resources for disasters, and specialized programs, accounted for $25.832 \%$, $13.757 \%, 7.658 \%, 7.060 \%$, and $6.684 \%$ of the variance of the HDPI, respectively. The internal consistency of the other subscales of the HDPI was calculated at $0.760,0.720,0.610,0.368$, and 0.478 , respectively. Moreover, considering the fact that the acceptable internal consistency is within the range of 0.7-0.9 ( 17 ), only the first and second factors fell in the acceptable domain (Tables 9).

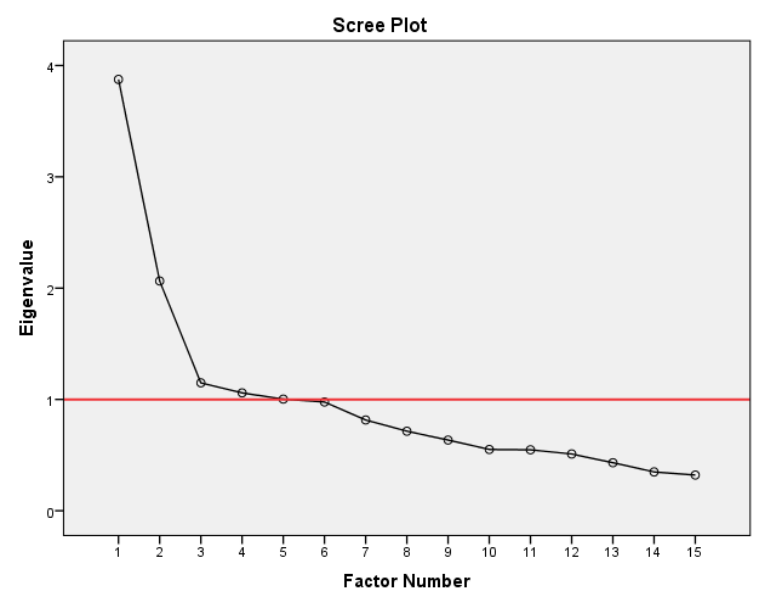

Diagram 1. Cattell's scree test 


\begin{tabular}{|c|c|c|c|c|c|}
\hline Components & 1 & 2 & 3 & 4 & 5 \\
\hline \multicolumn{6}{|l|}{ Factor one: Vulnerability reduction $(\alpha=0.760)$} \\
\hline $\begin{array}{l}\text { 4) Taking measures for the reinforcement of the house buildings in case of not being } \\
\text { reinforced }\end{array}$ & 0.848 & & & & \\
\hline $\begin{array}{l}\text { 3) Having evaluated the house building strength against earthquakes by a specialist during } \\
\text { the last year }\end{array}$ & 0.810 & & & & \\
\hline $\begin{array}{l}\text { 6) Having taken measures for the reduction of the vulnerability of house nonstructural } \\
\text { factors during the last year }\end{array}$ & 0.641 & & & & \\
\hline 5) Having evaluated house nonstructural vulnerability to earthquakes during the last year & 0.630 & & & & \\
\hline \multicolumn{6}{|l|}{ Factor two: Making plans for disaster $(\alpha=0.720)$} \\
\hline 1) Having held planning sessions for confronting disasters in the family during the last year & & 0.868 & & & \\
\hline 2) Important disasters risk maps drawn by the family & & 0.796 & & & \\
\hline 9) Having an evacuation plan in the family for emergency and disaster conditions & & 0.559 & & & \\
\hline \multicolumn{6}{|l|}{ Factor three: Family empowerment $(\alpha=0.610)$} \\
\hline 15) Emergency and disaster exercises by the family during the last year & & & 0.775 & & \\
\hline $\begin{array}{l}\text { 11) Family members' familiarity with the early warnings of the region's important } \\
\text { hazards, such as floods and storms }\end{array}$ & & & 0.638 & & \\
\hline 13) Completion of a first aid course at least by one of the family members during the last year & & & 0.577 & & \\
\hline 14) Family participation in disaster management programs in the neighborhood & & & 0.464 & & \\
\hline \multicolumn{6}{|l|}{ Factor four: Preparation of resources for disaster $(\alpha=0.368)$} \\
\hline 12) Existence of fire extinction tools in the house & & & & 0.791 & \\
\hline 7) Existence of emergency and disaster kits in the house & & & & 0.679 & \\
\hline \multicolumn{6}{|l|}{ Factor five: Specialized programs $(\alpha=0.476)$} \\
\hline 8) Having a communication plan in the family for emergency and disaster conditions & & & & & \\
\hline $\begin{array}{l}\text { 10) Having a program for helping vulnerable groups in the family for emergency and } \\
\text { disaster conditions }\end{array}$ & & & & & $\begin{array}{l}0.843 \\
0.547\end{array}$ \\
\hline
\end{tabular}

\section{Discussion}

In many of the studies carried out in Iran and other countries on family preparedness for disasters, instruments with unclear reliability and validity $(r-\Delta$, $19, Y \cdot)$ have been used. Therefore, the current study investigated the validity and reliability of the HDPI. The internal consistency of the HDPI was calculated at 0.786 which was a relatively appropriate value. Although the HDPI is relatively reliable, the presence of the items that are in correlations below 0.3 (i.e., items 7 and 12) in this instrument makes its homogeneity challenging; in fact, these items should be removed from the instrument ( $r)$ ). Additionally, if an item is observed with no correlation above 0.3 at least with one of the other items in the matrix of the items, it should be omitted $(1 \wedge)$ which was again true for the items numbered 7 and 12 . On the other hand, if the correlation coefficient between the two items is reported above 0.7 , one of the items should be eliminated from the inventory ( $\left.Y^{r}\right)$; nevertheless, there was not such an item in the HDPI.

The results of the present study indicated that changes should be made to HDPI content. Some of the words and combinations are odd and specialized, making it difficult to be understood by the households. Therefore, the face validity of this instrument was not firmly proved. Moreover, changes in the scoring type from two-choice form to spectral form and merging of some of the items can increase the validity of the instrument. Furthermore, considering the fact that the S-CVI/Ave was lower than the acceptable level for the HDPI, the items of this instrument should be revised in terms of three scales, namely relevancy, clarity, and simplicity. It seems that the instrument has largely concentrated on disasters, such as floods and earthquakes, and paid attention to all the hazards to a lower degree. In other words, generally, the content validity of this instrument is dubious with regard to the assessment of household preparedness for disasters.

The recognition that there was no presumption about the constitutional dimensions of the HDPI ( $\mathrm{V}$ ) and the items had the conditions required for factor analysis led to carry out exploratory factor analysis for investigating the construct validity of this instrument. Although five principal components or subscales, namely vulnerability reduction, making plans for disasters, family empowerment, preparation of resources for disasters, and specialized programs, were identified for the HDPI based on Cattell's scree test, the third, fourth, and fifth subscales lack the required internal consistency if a value within the range of 0.7-0.9 is considered the criterion for their internal consistency (17). In sum, there is a minor similarity between the components of this instrument and those used in the other studies. For instance, with regard to measures to be taken for preparation for earthquakes, Sakiroglu has defined a construct with subscales, such as the procurement of equipment, recognition of the location and method of disconnection and connection of the installations, measures to be taken for nonstructural reinforcement, planning for emergency exit, and interventions for acquiring further knowledge of the preparedness-related cases $\left(r^{r}\right)$. Page et al. also considered a construct with two subscales of having a program for responding to disasters and procuring the equipment in emergency conditions regarding preparedness ( $Y$ F). 
In another study, Murphy et al. regarded the provision of equipment, development of an emergency plan, and acceptance of the recommendations of relevant authorities as the subscales of emergency preparedness ( $r \Delta)$. Henderson et al. defined a construct with subscales, such as having a program for emergency conditions, emergency call information, information related to individual health, insurance, emergency conditions' reserves, and program for pets in terms of preparedness in disasters ( $r$ ). In a study carried out by Ardalan et al., an instrument was also used with six subscales for the evaluation of household preparedness for earthquakes, namely household preparedness knowledge, nonstructural safety measures, structural safety interventions, preparation exercises, risk map and communications, and safety skills ( 1 ). The US Council for Excellence in Government has considered subscales, such as knowledge and behavior for preparation in disasters ( $r \vee$ ). It can be approximately stated that the subscales of all these scales share some similar and some different matters with the items in HDPI subscales. It appears that none of these scales can perfectly assess such preparedness due to the absence of a coherent theory regarding household preparedness for disasters. On the other hand, the reliability and validity of most of these scales are unclear.

\section{Conclusion}

The obtained results of the present study demonstrated that although the HDPI is somewhat reliable, it does not have the required validity for the assessment of household preparedness for disasters. The items of this scale should be simpler and clearer in form; accordingly, families have no difficulty in understanding them. Specialized words should be substituted with understandable words. It seems that the scoring system of this index which is currently in the form of 0 and 1 should be transformed into a spectral form. In this case, some items of this index can be blended. On the other hand, most of the items should be revised in terms of three scales, namely relevancy, clarity, and simplicity. The constructs of the HDPI should be classified in order for its items to have the required internal consistency with respect to one another.

\section{Acknowledgments}

The authors would like to express their gratitude to their colleagues in Isfahan Red Crescent Society for providing insight and expertise that greatly helped in the current study.

\section{Footnotes}

Authors' Contribution: M.N. conceived the original idea and planned the study. H.K. supervised the project. M.N. and A.S. wrote and revised the manuscript. M.N. and G.A. performed the statistical analysis.

Conflict of Interests: The authors declare that there is no conflict of interest.

Funding/Support: The current study was financially supported by no institution.

\section{References}

1. Ardalan A, Sohrabizadeh S. Assessing households preparedness for earthquakes: an exploratory study in the development of a valid and reliable Persian-version tool. PLoS Curr. 2016;8:e. doi: 10.1371/currents.dis.ccc8697279713e66 887b928b839d0920. [PubMed: 26981326].

2. Joffe H, Perez-Fuentes G, Potts HW, Rossetto T. How to increase earthquake and home fire preparedness: the fix-it intervention. Natural Hazards. 2016;84(3):1943-65. doi: 10.1007/s11069-016-2528-1.

3. Chaney PL, Weaver GS, Youngblood SA, Pitts K. Household preparedness for tornado hazards: The 2011 disaster in DeKalb County, Alabama. Weath Clim Soci. 2013;5(4):345-58. doi: 10.1175/WCAS-D-12-00046.1.

4. Der-Martirosian C, Strine T, Atia M, Chu K, Mitchell MN, Dobalian A. General household emergency preparedness: a comparison between veterans and nonveterans. Prehosp Disaster Med. 2014;29(2):134-40. doi: 10.1017/S1049023X 1400020X. [PubMed: 24642181].

5. Murti M, Bayleyegn T, Stanbury M, Flanders WD, Yard E, Nyaku $\mathrm{M}$, et al. Household emergency preparedness by housing type from a Community Assessment for Public Health Emergency Response (CASPER), Michigan. Disaster Med Public Health Prep. 2014;8(1):12-9. doi: 10.1017/dmp.2013.111. [PubMed: 24524350].

6. Chan EY, Kim JH, Lin C, Cheung EY, Lee PP. Is previous disaster experience a good predictor for disaster preparedness in extreme poverty households in remote Muslim minority based community in China? J Immigr Minor Health. 2014;16(3):46672. doi: 10.1007/s10903-012-9761-9. [PubMed: 23264186].

7. Uscher-Pines L, Chandra A, Acosta J. Household preparedness is not enough: the challenges and opportunities in assessing community readiness for disasters. J Public Health Manag Pract. 2013;19:S70-6. doi: 10.1097/PHH.0b013e318294ea11. [PubMed: 23903399].

8. Ardalan A. Institutional approach in developing health emergency preparedness: the case of I.R.Iran. 7th International Congress on Health in Emergencies and Disasters, Tehran, Iran; 2016.

9. De Vaus D. Survey in Social Research,(2. Basim). London, England; 1990.

10. Najafi F, Kheiry B. Investigating the impact of country of origin on customer behavior: investigation of the moderating roles of product involvement and product familiarity on product evaluation and customer behavioral intentions. J Market Manag. 2013;7(17):37-60.

11. Azadian S, Shirali GA, Saki A. Designing a questionnaire to assess crisis management based on a resilience engineering approach. Jundishapur J Health Sci. 2014;6(1):245-56.

12. Polit DF, Beck CT, Owen SV. Is the CVI an acceptable indicator of content validity? Appraisal and recommendations. Res Nurs Health. 2007;30(4):459-67. doi: 10.1002/nur.20199. [PubMed: 17654487].

13. Hyrkäs K, Appelqvist-Schmidlechner K, Oksa L. Validating an instrument for clinical supervision using an expert panel. Int J Nurs Stud. 2003;40(6):619-25. doi: 10.1016/s00207489(03)00036-1. [PubMed: 12834927].

14. Rubio DM, Berg-Weger M, Tebb SS, Lee ES, Rauch S. Objectifying content validity: Conducting a content validity study in social work research. Soci Work Res. 2003;27(2):94-104.

15. Lang WS, Wilkerson JR. Accuracy vs .Validity, Consistency vs. 
Reliability, and Fairness vs. Absence of Bias: A Call for Quality. Paper Presented at the Annual Meeting of the American Association of Colleges of Teacher Education (AACTE), New Orleans, LA; 2008.

16. Nunnally JC. Psychometric theory 3E: Tata McGraw-Hill Education; 1994.

17. Henson RK, Roberts JK. Use of exploratory factor analysis in published research: Common errors and some comment on improved practice. Educat Psychol Measur. 2006;66(3):393416. doi: $10.1177 / 0013164405282485$.

18. Kellar SP, Kelvin EA. Munro's statistical methods for health care research: Wolters Kluwer Health/Lippincott Williams \& Wilkins; 2013

19. McClure J, Walkey F, Allen M. When earthquake damage is seen as preventable: Attributions, locus of control and attitudes to risk. Appl Psychol. 1999;48(2):239-56. doi: 10.1111/j.14640597.1999.tb00060.x.

20. Showalter PS. Prognostication of doom: An earthquake prediction's effect on four small communities. Int J Mass Emergenc Disasters. 1993;11(3):279-92.

21. Clark LA, Watson D. Constructing validity: Basic issues in objective scale development. The University of Lowa. 2016.
22. Hayton JC, Allen DG, Scarpello V. Factor retention decisions in exploratory factor analysis: A tutorial on parallel analysis. Organization Res Methods. 2004;7(2):191-205. doi: 10.1177/1094428104263675.

23. Sakiroğlu M. Variables related to earthquake Preparedness Behavior. A Thesis, Department of Psychology, Middle East Technical University, Ankara, Turkey; 2005.

24. Page L, Rubin J, Amlôt R, Simpson J, Wessely S. Are Londoners prepared for an emergency? A longitudinal study following the London bombings. Biosecur Bioterror: 2008;6(4):309-19. doi: 10.1089/bsp.2008.0043. [PubMed: 19117430].

25. Murphy ST, Cody M, Frank LB, Glik D, Ang A. Predictors of emergency preparedness and compliance. Disaster Med Public Health Prep. 2009;3(2):1-10. doi: 10.1097/DMP.0b013e 3181a9c6c5. [PubMed: 19590429].

26. Henderson TL, Miller S, Hendrix J, Dinh M. Checklist for disaster preparedness. Oklahoma State University; 2010.

27. Council for Excellence in Goverment. Are We Ready?: Introducing the Public Readiness Index: a Survey-based Tool to Measure the Preparedness of Individuals, Families and Communities: The Office; 2006. 